industry, energy and dexterity, and perhaps ambition, the student must be entitled to decide for himself in what direction his work might be expected to bring its own reward. In coming to a decision personal trends must be given due weight :

1. There are those whose chief thrill comes from research, in following out a line of thought by experiment and logical reasoning, hoping in the end to reach a worthwhile result. For them medicine provides an ever-widening horizon, each fresh discovery a steppingstone to the next.

2. Others are thrilled by imparting instruction on established facts and possible theories to individuals or groups. We speak of the "born teachers," whose gifts both bring and bestow enjoyment.

3. Others still are attracted by the thrill of being the bearers of hope and confidence to the sick as they are found in the wards and out-patient departments of our hospitals. Valuable equipment for these is what, for want of a better term, we call clinical instinct, and for them there is again a wide choice among the many departments of clinical work, each with its own peculiar attraction.

It is my experience that all these qualities and ideals are seldom combined in a single individual, and at a time when money prizes are unlikely in the future to compare with those of the past, but where for every medical graduate a livelihood is assured, a young man or woman should be encouraged to follow that course in which the work itself would be a continuous joy, and from which he or she might be expected in the end to obtain the maximum of individual satisfaction. If I might be permitted to end on a personal note it would be one of thanks to an old teacher, the late Professor James Lindsay, who at a critical moment gave me advice which I pass on to those faced to-day with the entrancing and decisive problems of youth.-I am, etc., Beifast.

S. T. IRWIN.

\section{Prevention of Venereal Disease}

SIR,-The numerous correspondents in the Journal of July 31 (p. 268 et seq.) appear to have missed the essential points of Lord Horder's letter (July 17, p. 171), and the simplest way to reply to the various issues raised in their letters is to restate the main heads of the campaign. The campaign of the N.S.P.V.D. is directed towards the enlightenment of the public on the following matters.

1. Over a long period of years the abundantly proved fact that V.D. is easily preventable has been prevented from reaching the public, and in spite of lavish public expenditure on other methods V.D. has increased.

2. The Report of the Government-appointed Trevethin Committee settled once for all the scientific fact that V.D. is easily preventable. Abundant scientific evidence was laid before that committee, and this was confirmed by overwhelming evidence from myself and others as the result of wide experience in reducing V.D. in the Services. Dramatic reduction in V.D. has always followed the introduction of reasonably effective selfdisinfection.

On the subject of practicability for the average person the Report says : "We see no reason to doubt that an intelligent man, if furnished with reasonable instructions, could in favourable conditions effectively disinfect himself." A study of the actual instructions will convince anyone that no high degree of intelligence is required. The process is so simple that "official skilled supervision" of the disinfection is obviously superfluous. Practical experience, moreover, has shown conclusively that civilians will not seek such assistance, and that in the case of the Services the introduction of supervision and the unnecessary elaboration of the procedure have been the chief causes of the apparent lack of success on account of evasion. Officially supervised disinfection never has been, and never will be, successful on account of the psychological factors involved.

3. The Trevethin Committee Report replies effectively to the allegation that knowledge about preventives would lead to increased promiscuity. On this subject the Report says : "It is urged by some that any system of disinfection would tend to increase the number of exposures and to raise the disease rate. We have received no evidence of facts in support of this view, and we are inclined to think that those who hold it attach too much weight to the deterrent effect of the fear of the disease."

Conclusive evidence was supplied by myself and others that a c)mpaign of prevention of self-disinfection in any area was often followed by a decrease in promiscuity, because the instructions given furnished the plainest proof of the danger of infection.
4. Not only is the spread of this important knowledge prevented but if it does leak out the law prevents any practical application. Incredible as it may seem, it is actually illegal for a chemist to sell to any customer the necessary materials for prevention accompanied by instructions for use. This continues in spite of the fact that the Trevethin Report in 1923 recommended that the law should be altered. Not content with compulsory ignorance the obstructionists prevent any useful application of any leakage of information. Could fanaticism go further ?-I am, etc.,

London, W.1.

R. A. LYSTER,

Chairman. National Society for the Prevention of Venereal Disease.

SIR,- Statistics can be used to prove most things, and there are statistics to prove that prophylaxis is useless in the prevention of venereal disease. One instance will serve. In a certain distinguished battalion in Delhi 18 men contracted hard chancres in one month. Inquiry proved that all these men had used the unit prophylactic ablution centre, and had stated so in the prescribed form which men who contracted V.D. had to complete. This would seem to prove that prophylaxis was useless. Investigation of the forms, however, showed that the men had all exposed themselves to infection at $10 \mathrm{p} . \mathrm{m}$. on various evenings during the month, had each used the P.A. room 15-20 minutes later, and that each had reported at the medical inspection room at 8 a.m. on the morning following exposure with a hard chancre.

I took a close interest in the prevention of venereal disease during the eighteen and half years I spent in India, most of it as a hygiene officer, and I wish to say that $I$ have seldom found a British soldier in hospital with V.D. who had not used the P.A.C., but also that $I$ have never, after inquiry, found a soldier in hospital with V.D. who had used the prophylactic ablution centre at the proper time. The centre had been used after the disease showed itself. On my visits I always used to ask the P.A. room orderlies the same question, "How many men have you known getting V.D. who had used the P.A. room at the proper time?"-i.e., within an hour or so after exposure-and the answer was invariably the same, "None, sir." Early washing with soap and water would probably prevent 99 cases out of a 100 . The use of mercurial cream after washing would make it as near a certainty as makes no difference.

Owing to the circumstances prevailing in a British division in India during the war it was decided not to establish unit P.A. rooms. Instead, the likelihood of infection if they exposed themselves was impressed on all ranks, and also the value of thorough washing on return to their quarters, using their own soap and towel, and then applying mercurial cream. Steps were taken at the same time to see that prophylactic packets were available for all, easily and unobtrusively. The results fully justified these measures.-I am, etc.,

Publio Health Branch.

Control Commission for Germany.

W. Strelley Martin.

\section{Whooping-cough and Measles}

SIR,- In the spring of 1938 an epidemic of measles (morbilli) coincided here with an epidemic of whooping-cough. Of 57 consecutive cases of measles seen by me, 55 were children and 2 were adults. Among the 55 children there were 46 cases of measles alone, 7 of measles developing during whoopingcough, and 2 of whooping-cough developing during measles.

Of the seven who had whooping-cough first and measles during its course all took a normal course without complications, and in two cases there was a suggestion that the whoopingcough was improved by the measles. Of the two with measles first and whooping-cough during its course one progressed to bronchopneumonia and the other was normal. Of the 46 cases of measles alone ten developed some complication or ran an abnormal course. Two had asthma at the height of the rash never having had it before, one developed a persistent nasal catarrh, two developed erythema nodosum in the second and third weeks respectively with fever, one had joint and abdominal pains for four days before the rash came out and was unable to pass water during the third and fourth days of the rash, two had coughs persisting for more than 14 days from the commence- 